\title{
PENGARUH KOMUNIKASI, MOTIVASI, DAN LINGKUNGAN KERJA FISIK TERHADAP DISIPLIN KERJA KARYAWAN
}

\author{
Ni Wayan Putri Gresida ${ }^{1}$ \\ I Wayan Mudiartha Utama ${ }^{2}$
}

\author{
${ }^{1,2}$ Fakultas Ekonomi dan Bisnis Universitas Udayana (Unud), Bali, Indonesia \\ email:pgresida@yahoo.com
}

\begin{abstract}
ABSTRAK
Tujuan penelitian ini adalah untuk menjelaskan pengaruh komunikasi, motivasi, dan lingkungan kerja fisik terhadap disiplin kerja karyawan. Penelitian ini dilakukan di Warung Mina Cabang Peguyangan Denpasar. Jumlah sampel yang diambil sebanyak 45 orang karyawan, dengan metode sampling jenuh. Pengumpulan data dilakukan melalui wawancara dan kuesioner. Teknik analisis yang digunakan adalah regresi linear berganda. Berdasarkan hasil analisis menunjukkan bahwa komunikasi, motivasi, dan lingkungan kerja fisik berpengaruh positif dan signifikan terhadap disiplin kerja karyawan. Warung Mina Cabang Peguyangan Denpasar diharapkan lebih memperhatikan komunikasi sesama karyawan, meningkatkan penjagaan kesehatan karyawannya, seperti memberi jaminan kesehatan, dan melakukan penataan ruangan agar karyawan merasa nyaman dalam bekerja. Penataan ruangan akan mempermudah gerak karyawan dalam melakukan pekerjaan dengan cepat, tepat, dan akurat untuk membantu meningkatkan disiplin kerja karyawan.

Kata kunci: komunikasi, motivasi, lingkungan kerja fisik, disiplin kerja
\end{abstract}

\begin{abstract}
The purpose of this study is to explain the influence of communication, motivation, and physical work environment on employee work discipline. This research was conducted at the Warung Mina Peguyangan Denpasar Branch. The number of samples taken was 45 employees, with a saturated sampling method. Data collection is done through interviews and questionnaires. The analysis technique used is multiple linear regression. Based on the results of the analysis show that communication, motivation, and physical work environment have a positive and significant effect on employee work discipline. The Peguyangan Denpasar Branch Mina Warung is expected to pay more attention to fellow employees' communication, improve the health care of their employees, such as providing health insurance, and arranging rooms so that employees feel comfortable at work. Room arrangement will make it easier for employees to do work quickly, accurately, and accurately to help improve employee work discipline.

Keywords: communication, motivation, physical work environment, work discipline
\end{abstract}




\section{PENDAHULUAN}

Dalam era globalisasi saat ini, segala aspek kehidupan dituntut untuk bersaing menunjukkan sikap terbaik, karena yang terbaiklah yang akan dipilih untuk dapat bersaing dalam pasar. Khususnya untuk organisasi yang bergerak di bidang jasa, maka organisasi tersebut harus mampu memberikan pelayanan yang terbaik. Pelayanan tersebut bersumber dari sumber daya manusia. Sumber daya manusia merupakan harta atau aset yang paling berharga dan paling penting yang dimiliki oleh suatu organisasi atau perusahaan, karena keberhasilan suatu organisasi atau perusahaan sangat ditentukan oleh unsur manusia (Ardana dkk., 2014: 3), maka setiap organisasi harus mampu mengatur proses pemanfaatan sumber daya manusia yang dimiliki guna kelangsungan hidup organisasi.

Dalam menciptakan sumber daya manusia yang berkualitas perlu adanya pembinaan disiplin kerja dalam tiap diri karyawan pada organisasi yang merupakan tindakan manajemen untuk mendorong para anggotanya untuk memenuhi berbagai ketentuan (Iswara \& Sudharma, 2013). Disiplin merupakan salah satu fungsi manajemen sumber daya manusia yang penting dan merupakan kunci tercapainya tujuan perusahaan (Susita et al., 2017). Organisasi harus melakukan pengawasan guna mengontrol disiplin kerja karyawan sehari-hari, karena tingkat disiplin kerja akan berdampak positif pada pencapaian tujuan organisasi.

Menurut Wirawan (2009: 138) pendisiplinan bertujuan untuk memotivasi karyawan agar mentaati peraturan perusahaan, mempertahankan hubungan saling menghormati antara bawahan dan atasan, meningkatkan hasil kerja, meningkatkan moril, semangat kerja, etos kerja, efektivitas dan efisien kerja, serta meningkatkan kedamaian dan kewargaorganisasian. Saydam (2010: 63) menyatakan, menurunnya disiplin kerja karyawan disebabkan oleh tingginya angka absensi, sering terlambatnya dan pulang lebih cepat dari jam yang ditentukan, menurunnya semangat dan gairah kerja, tidak tercapainya target perusahaan yang telah diprogramkan, serta merosotnya produktivitas dan hasil pekerjaan. Disiplin adalah sikap seseorang untuk mematuhi dan mentaati segala macam norma-norma peraturan yang berlaku di sekitarnya (Hasibuan, 2009: 56). Suniastuti \& Suana (2012) menyatakan bahwa disiplin yang baik mencerminkan adanya tanggung jawab karyawan terhadap tugas yang diberikan.

Mangkunegara (2013:145) menyatakan bahwa disiplin yang baik dibentuk dari komunikasi yang baik dari seseorang. Komunikasi mendukung motivasi dengan mengklarifikasi pekerja apa yang perlu dilakukan atau seberapa baik yang mereka lakukan (Atambo \& Momanyi, 2016). Ketika komunikasi berhenti, kegiatan perusahaan dan kegiatan individual tidak akan terkoordinasi dalam suatu organisasi (Shonubi \& Akintaro, 2016). Oleh karena itu, komunikasi sangat penting untuk karyawan dalam proses penyampaian informasi (pesan, ide, gagasan) dari satu pihak kepada pihak lain. Raymond (2010: 43) menyatakan bahwa komunikasi adalah proses pemilihan dan pengiriman simbol-simbol sedemikian rupa agar membantu pendengar membangkitkan respon dari pemikiran yang serupa dengan yang dimaksudkan oleh komunikator.

Penelitian dari Suaip \& Astuti (2015) menyatakan bahwa komunikasi berpengaruh signifikan terhadap disiplin kerja pegawai. Dessy \& Wibawa (2015) 
menyatakan bahwa komunikasi secara simultan dan secara parsial berpengaruh terhadap disiplin karyawan. Demikian juga penelitian dari Dila \& Rochmah (2015) menyatakan bahwa tingkat efektivitas komunikasi berpengaruh terhadap kedisiplinan pegawai. Kurangnya komunikasi antara atasan dan bawahan atau antar sesama bawahan juga mengakibatkan kurangnya motivasi para karyawan. Dengan adanya komunikasi yang baik, maka akan lebih mudah bagi atasan untuk memotivasi karyawan.

Martoyo (2010: 45) menyatakan bahwa motivasi merupakan faktor yang mempengaruhi disiplin kerja karyawan. Proses motivasi sangat tergantung pada kemampuan pemimpin untuk mempengaruhi bawahan dalam upaya untuk mewujudkan tujuan organisasi (Kasim et al. 2016). Tanpa motivasi, seorang karyawan tidak akan merasa antusias menyelesaikan pekerjaannya dan juga mudah putus asa apabila mengalami kegagalan. Motivasi adalah dorongan dari internal (diri sendiri), sesuatu yang menyebabkan, mendistribusikan dan merupakan latar belakang mendasari perilaku seseorang (Amiroso \& Mulyanto, 2015).

Motivasi yang tinggi dapat secara langsung berpengaruh terhadap disiplin kerja karyawan. Muharsih (2016) menyatakan bahwa terdapat pengaruh yang signifikan antara motivasi kerja terhadap disiplin kerjakaryawan. Zahari (2015) menyatakan bahwa motivasi memiliki pengaruh positif dan signifikan terhadap disiplin kerja. Sugiyatmi dkk. (2016) menyatakan bahwa motivasi kerja berpengaruh positif dan signifikan terhadap disiplin kerja karyawan. Dessy \& Wibawa (2015) menyatakan bahwa variabel motivasi kerja secara simultan dan secara parsial berpengaruh terhadap disiplin karyawan. Kurangnya motivasi dari atasan bisa mengakibatkan karyawan lalai dalam menjaga kebersihan lingkungan di sekitar tempat kerja.

Lingkungan kerja merupakan faktor utama yang mempengaruhi kinerja karyawan. Nitisemito (2010: 119) menyatakan lingkungan kerja fisik adalah segala sesuatu di sekitar para pekerja yang mempengaruhi pekerja dalam menjalankan tugas-tugas yang diberikan. Lingkungan kerja fisik diukur dengan indikator penerangan, suhu udara, penggunaan warna, suara dalam ruang kerja, kebersihan, ruang gerak, dan keamanan (Ahyari, 2011: 76). Dalam penelitian yang dilakukan oleh Permana dkk. (2015) menyatakan bahwa lingkungan kerja fisik berpengaruh positif dan signifikan terhadap disiplin kerja. Permata \& Mujiati (2017) menyatakan bahwa lingkungan kerja fisik berpengaruh positif dan signifikan terhadap disiplin kerja. Penelitian yang dilakukan oleh Puspitasari dkk. (2017) menyatakan bahwa secara parsial menunjukkan bahwa lingkungan kerja berpengaruh terhadap disiplin kerja.

Warung Mina adalah perusahaan di bidang kuliner yang menjual masakan ikan segar dan mengusung suasana pedesaan. Warung Mina memiliki 13 outlet resmi di Bali. Penelitian dilakukan di Warung Mina Cabang Peguyangan Denpasar dikarenakan Warung Mina Cabang Peguyangan berupaya untuk meningkatkan disiplin kerja karyawan sehingga diharapkan dapat meningkatkan kualitas pelayanan kepada konsumen. Pelaksanaan disiplin kerja yang dilakukan Warung Mina Cabang Peguyangan Denpasar dapat dilihat dari total waktu kerja karyawan yaitu 7 jam kerja di mana dengan waktu istirahat 1 jam setelah 4 jam 
kerja. Waktu jam kerja karyawan terbagi menjadi 3 shift yaitu : shift pagi dari pukul $08.00 \mathrm{~s} / \mathrm{d} 16.00$, shift sore dari pukul $14.30 \mathrm{~s} / \mathrm{d} 22.30$, dan shift middle dari pukul $11.00 \mathrm{~s} / \mathrm{d}$ 19.00. Karyawan harus hadir setiap hari kerja kecuali pada kondisi tertentu dengan alasan sakit atau ijin serta untuk libur karyawan sebanyak 4 kali dalam sebulan. Karyawan Warung Mina Cabang Peguyangan dituntut untuk menunjukkan kedisiplinan. Menurut Handoko (2014: 26) tingkat absensi (sakit, ijin, dan alpa) dapat mencerminkan tingkat disiplin kerja karyawan. Tingkat absensi karyawan Warung Mina Cabang Peguyangan dapat dilihat pada Tabel 1 .

Tabel 1.

Tingkat Absensi Karyawan Warung Mina Cabang Peguyangan Periode Januari - Desember Tahun 2017

\begin{tabular}{|c|c|c|c|c|c|c|}
\hline Bulan & $\begin{array}{c}\text { Hari } \\
\text { Kerja }\end{array}$ & $\begin{array}{l}\text { Jumlah } \\
\text { Karyawan } \\
\text { (Orang) }\end{array}$ & $\begin{array}{l}\text { Jumlah } \\
\text { Hari Kerja } \\
\text { Seharusnya }\end{array}$ & $\begin{array}{l}\text { Absensi } \\
\text { (Hari) }\end{array}$ & $\begin{array}{l}\text { Jumlah } \\
\text { Kehadiran } \\
\text { Karyawan } \\
\text { (Hari) }\end{array}$ & $\begin{array}{l}\text { Persentase } \\
\text { Absensi } \\
\text { Karyawan } \\
(\%)\end{array}$ \\
\hline
\end{tabular}

\begin{tabular}{|c|c|c|c|c|c|c|}
\hline 1 & 2 & 3 & $4=2 \times 3$ & 5 & $6=4-5$ & $\begin{array}{c}7=5 / 4 \times 100 \\
\%\end{array}$ \\
\hline Januari & 31 & 45 & 1395 & 51 & 1344 & 3,65 \\
\hline Pebruari & 28 & 45 & 1260 & 64 & 1196 & 5,07 \\
\hline Maret & 31 & 45 & 1395 & 44 & 1351 & 3,15 \\
\hline April & 30 & 45 & 1350 & 98 & 1252 & 7,25 \\
\hline Mei & 31 & 45 & 1395 & 116 & 1279 & 8,31 \\
\hline Juni & 30 & 45 & 1350 & 56 & 1294 & 4,14 \\
\hline Juli & 31 & 45 & 1395 & 150 & 1245 & 10,75 \\
\hline Agustus & 31 & 45 & 1395 & 76 & 1319 & 5,44 \\
\hline September & 30 & 45 & 1350 & 49 & 1301 & 3,62 \\
\hline Oktober & 31 & 45 & 1395 & 71 & 1324 & 5,08 \\
\hline Nopember & 30 & 45 & 1350 & 97 & 1253 & 7,18 \\
\hline \multirow[t]{2}{*}{ Desember } & 31 & 45 & 1395 & 48 & 1347 & 3,44 \\
\hline & Jumlah & & $\begin{array}{r}16425 \\
\end{array}$ & 920 & 15505 & 67,08 \\
\hline
\end{tabular}

Sumber: Data diolah, 2018

Menurut Mudiartha dkk. (2001: 93) rata-rata tingkat absensi antara 2-3 persen perbulan masih dianggap baik, sedangkan tingkat absensi yang mencapai 15-20 persen per bulan sudah menunjukkan gejala disiplin kerja karyawan yang sangat buruk. Berdasarkan Tabel 1. dapat dinyatakan bahwa persentase karyawan setiap bulannya mencapai di atas 3 persen. Tingkat absensi terendah terjadi pada bulan Maret yaitu sebesar 3,15 persen sedangkan pada bulan Juli mengalami peningkatan hingga 10,75 persen. Rata-rata tingkat absensi karyawan mencapai 5,59 persen mengindikasikan masih adanya karyawan yang kurang disiplin dalam bekerja.

Berdasarkan hasil wawancara mengenai disiplin kerja yang dilakukan di Warung Mina Cabang Peguyangan Denpasar, juga mengindikasikan bahwa 
terdapat beberapa masalah yang dikemukakan oleh 15 orang karyawan yaitu, 3 orang menyatakan sering melanggar peraturan mengenai jadwal kerja yang berlaku di perusahaan, karyawan sering terlambat datang ke kantor dan pulang sebelum jam kerja selesai sebanyak 10 kali. 4 orang karyawan menyatakan kurang berhati-hati dalam menggunakan alat kerja sebanyak 7 kali, sehingga sering terjadi kerusakan pada alat-alat kerja. 3 orang karyawan menyatakan tidak mengerjakan tugas sesuai instruksi dengan aturan yang berlaku sebanyak 9 kali, tidak menyelesaikan tugasnya dengan tepat waktu dan sering menghindari tanggung jawab. 5 orang karyawan menyatakan jarang menggunakan atribut kantor sebanyak 14 kali seperti seragam, id card sesuai aturan yang berlaku, tidak meminta ijin apabila tidak masuk kantor.

Berdasarkan hasil wawancara yang dilakukan pada karyawan Warung Mina Cabang Peguyangan Denpasar, mengindikasikan bahwa terdapat permasalahan mengenai komunikasi yaitu kurangnya kelancaran komunikasi seperti, kurang jelasnya informasi dari atasan yang mengakibatkan ketidakselarasan dalam penyampaian informasi, serta antarsesama bawahan seperti, kesalahan penerimaan pesan oleh karyawan yang menyebabkan pesanan makanan tidak sesuai dengan pesanan.

Berkaitan dengan kurangnya kelancaran komunikasi yang mengakibatkan ketidakselarasan dalam penyampaian informasi juga mengakibatkan kurangnya motivasi karyawan dalam bekerja. Karyawan jarang mendapatkan motivasi dari atasan sehingga pekerjaan mereka sering tidak terarah, pekerjaan tidak selesai tepat waktu, dan para karyawan menjadi tidak termotivasi dalam menjaga kebersihan lingkungan di tempat kerja. Permasalahan yang berkaitan dengan lingkungan kerja fisik yaitu, sampah yang berserakkan, tempat sampah yang selalu penuh, suara bising dan suhu udara panas pada ruangan dapur sehingga dapat menurunkan kondisi fisik dan kondisi mental karyawan. Dari permasalahan itu, terlihat bahwa masih adanya disiplin kerja karyawan yang terbilang kurang baik di Warung Mina Cabang Peguyangan Denpasar.

Disiplin pada dasarnya adalah kemampuan mengendalikan diri dalam bentuk tidak melakukan tindakan yang tidak sesuai dan mendukung sesuatu yang telah dibuat (Mangkunegara \& Octorend, 2015). Sarwani (2016) menyatakan bahwa disiplin adalah kekuatan yang berkembang di tubuh para karyawan itu sendiri yang menyebabkan dia menyesuaikan diri secara sukarela tunduk pada keputusan, peraturan, dan penilaian kinerja. Kheruniah (2013) menyatakan bahwa, disiplin merupakan suatu kondisi penting yang menunjukkan nilai-nilai ketaatan, kepatuhan, kesetiaan, ketenteraman, keteraturan, dan ketertiban karena dengan adanya pendisiplinan dari seluruh anggota maka suatu organisasi dapat mencapai tujuannya. Disiplin kerja dalam perusahaan akan membuat karyawan dapat menjalankan tugas-tugas yang dibebankan kepadanya dengan baik. Karyawan yang disiplin dan patuh terhadap norma-norma yang berlaku dalam perusahaan dapat meningkatkan produktivitas dan prestasi kerja karyawan yang bersangkutan. Martoyo (2010: 60) menyatakan bahwa ada beberapa faktor yang mempengaruhi disiplin kerja antara lain, motivasi, pendidikan dan pelatihan, kepemimpinan, tingkat kesejahteraan yang diberikan oleh perusahaan, dan penegakkan disiplin. 
Menurut Muharsih (2016) mengemukakan faktor-faktor disiplin kerja yaitu kepribadian dan lingkungan.

Elqadri et al. (2015) menyatakan bahwa disiplin kerja adalah alat yang digunakan manajer untuk berkomunikasi dengan karyawan agar mereka bersedia untuk mengubah sikap dan sebagai upaya dalam meningkatkan kesadaran dan kesediaan karyawan untuk menaati peraturan perusahaan dan norma-norma sosial yang berlaku. Komunikasi adalah aktivitas manusia yang menghubungkan orangorang dan menciptakan hubungan (Femi, 2014). Mudasir et al. (2014) menyatakan, komunikasi adalah alat penting dalam kehidupan sehari-hari untuk menafsirkan sebuah ide dengan cara yang dimaksudkan oleh pembicara. Raymond (2010: 47) menyatakan bahwa komunikasi adalah proses menyortir, memilih, dan pengiriman simbol-simbol sedemikian rupa agar membantu pendengar membangkitkan respon atau makna dari pemikiran yang serupa dengan yang dimaksudkan oleh komunikator. Ketika komunikasi berhenti, kegiatan perusahaan dan kegiatan individual tidak akan terkoordinasi dalam suatu organisasi (Shonubi \& Akintaro, 2016).

Suaip \& Astuti (2015) menyatakan bahwa variabel komunikasi berpengaruh signifikan terhadap disiplin kerja pegawai. Dessy \& Wibawa (2015) menyatakan bahwa variabel komunikasi secara simultan dan secara parsial berpengaruh terhadap disiplin karyawan. Demikian juga penelitian dari Dila \& Rochmah (2015) menyatakan bahwa tingkat efektivitas komunikasi berpengaruh terhadap kedisiplinan pegawai. Penelitian yang dilakukan oleh Andriani (2018) juga menyatakan bahwa komunikasi internal memiliki pengaruh positif dan signifikan terhadap disiplin kerja pegawai. Azis \& Muchtar (2016) menyatakan bahwa komunikasi organisasi berpengaruh signifikan terhadap disiplin kerja pegawai. Berdasarkan hasil empiris pada penelitian terdahulu, hipotesis yang dapat diajukan dalam penelitian ini adalah :

$\mathrm{H}_{1}$ : Komunikasi berpengaruh positif dan signifikan terhadap disiplin kerja karyawan.

Secara umum, motivasi hanya ditujukan kepada manajemen sumber daya manusia (Riyanto et al., 2017). Faktor utama yang mempengaruhi motivasi karyawan adalah kebutuhan karyawan (Yamsul et al., 2013). Motivasi juga dapat diartikan sebagai kekuatan pendorong yang dimaksudkan sebagai dorongan alami untuk memuaskan dan mempertahankan kehidupan (Syamsuri, 2017). Renah \& Setyadi (2014) menyatakan bahwa motivasi adalah keadaan batin yang memberi energi, mengaktifkan atau menstimulasi dan mengarahkan perilaku terhadap tujuan tertentu. Hasibuan (2009: 86) menyatakan motivasi merupakan suatu cara bagaimana mendorong gairah kerja bawahan agar mereka mau bekerja keras dengan memberikan semua kemampuan dan keterampilannya untuk mewujudkan tujuan perusahaan.

Ardana dkk. (2014: 193) motivasi adalah kekuatan yang mendorong seseorang untuk melakukan suatu tindakan yang ada secara internal dan eksternal yang bersifat positif dan negatif yang untuk mengarahkannya sangat bergantung kepada ketangguhan sang manajer. Pada dasarnya proses motivasi dapat digambarkan jika seseorang tidak puas akan mengakibatkan ketegangan, pada akhirnya akan mencari jalan atau tindakan untuk memenuhi dan terus mencari 
kepuasan yang menurut ukurannya sendiri sudah sesuai dan harus terpenuhi. Salah satu teori motivasi yang dikenal, yaitu "Teori Hirarki Kebutuhan", teori ini yang membahas tentang motivasi adalah yang dikembangkan oleh Abraham Maslow yang disebut Teori Hirarki Kebutuhan. Mangkunegara \& Octorend (2015) menyatakan bahwa teori yang dikembangkan Abraham Maslow yang berbunyi individu akan termotivasi melakukan apabila individu tersebut dapat memenuhi kebutuhannya pada saat itu.

Penelitian yang dilakukan oleh Muharsih (2016) menyatakan bahwa terdapat pengaruh yang signifikan antara motivasi kerja terhadap disiplin kerja karyawan. Zahari (2015) menemukan bahwa motivasi memiliki pengaruh positif dan signifikan terhadap disiplin kerja. Demikian juga penelitian dari Sugiyatmi dkk. (2016) menyatakan bahwa motivasi kerja berpengaruh positif dan signifikan terhadap disiplin kerja karyawan. Hasil penelitian dari Farid dkk. (2016) menyatakan bahwa motivasi kerja berpengaruh secara signifikan terhadap disiplin dan juga kinerja karyawan. Penelitian yang dilakukan oleh Kokom (2017) menyatakan bahwa motivasi berprestasi berpengaruh secara signifikan terhadap disiplin kerja pegawai. Berdasarkan hasil empiris pada penelitian terdahulu, hipotesis yang dapat diajukan dalam penelitian ini adalah :

$\mathrm{H}_{2}$ : Motivasi berpengaruh positif dan signifikan terhadap disiplin kerja karyawan.

Sedarmayanti (2014: 26) lingkungan kerja fisik adalah semua yang terdapat di sekitar tempat kerja yang dapat mempengaruhi karyawan baik secara langsung maupun tidak langsung, sedangkan Handoko (2014: 186) lingkungan kerja fisik adalah keseluruhan atau setiap aspek dari segala fisik yang mengelilingi atau mempengaruhi individu. Secara umum, lingkungan kerja fisik di dalam suatu perusahaan merupakan lingkungan di mana karyawan tersebut melaksanakan tugas dan pekerjaan sehari-hari. Sedarmayanti (2014: 27) menyatakan bahwa manusia akan mampu melaksanakan kegiatannya dengan baik sehingga dicapai suatu hasil yang optimal, apabila diantaranya ditunjang oleh suatu kondisi lingkungan yang sesuai. Lingkungan kerja fisik penting mendapatkan perhatian dari perusahaan karena dilihat dari peranannya lingkungan kerja merupakan salah satu faktor yang mempunyai pengaruh yang tidak kecil terhadap sumber daya manusia dalam suatu perusahaan.

Dalam penelitian yang dilakukan oleh Permana dkk. (2015) menyatakan bahwa lingkungan kerja fisik berpengaruh positif dan signifikan terhadap disiplin kerja. Penelitian yang dilakukan oleh Haryono dkk. (2016) menyatakan bahwa secara simultan lingkungan kerja terhadap kedisiplinan karyawan. Permata \& Mujiati (2017) menyatakan bahwa lingkungan kerja fisik berpengaruh positif dan signifikan terhadap disiplin kerja. Hasil penelitian yang dilakukan oleh Puspitasari dkk. (2017); Sugiyatmi dkk. (2016) menyatakan bahwa secara parsial menunjukkan bahwa lingkungan kerja berpengaruh terhadap disiplin kerja. Penelitian yang dilakukan oleh Andriani (2018) juga menyatakan bahwa lingkungan kerja memiliki pengaruh positif dan signifikan terhadap disiplin kerja pegawai. Berdasarkan hasil empiris pada penelitian terdahulu, hipotesis yang dapat diajukan dalam penelitian ini adalah :

$\mathrm{H}_{3}$ : Lingkungan kerja fisik berpengaruh positif dan signifikan terhadap disiplin kerja karyawan. 


\section{METODE PENELITIAN}

Penelitian ini dilaksanakan di Warung Mina Cabang Peguyangan Denpasar yang beralamat di Jalan Antasari No. 91, Peguyangan Kangin, Denpasar Utara, Bali. Dasar pertimbangan memilih Warung Mina Cabang Peguyangan karena terdapat permasalahan terhadap disiplin kerja karyawan setelah dilihat dari tingkat absensi karyawan dan diadakan wawancara dengan karyawan terlebih dahulu. Obyek dari penelitian ini adalah komunikasi, motivasi, lingkungan kerja fisik dan disiplin kerja karyawan.

Populasi dalam penelitian ini adalah seluruh karyawan Warung Mina Cabang Peguyangan Denpasar yang berjumlah 45 orang. Teknik pengambilan sampel dalam penelitian ini adalah sampling jenuh (saturated sampling), artinya seluruh anggota populasi dijadikan sampel penelitian.

Analisis statistika inferensial menggunakan metode regresi linear berganda. Analisis ini digunakan untuk mengetahui besarnya pengaruh variabel yaitu komunikasi, motivasi dan lingkungan kerja fisik terhadap disiplin kerja karyawan. Model regresi linear berganda ditunjukkan dengan persamaan seperti berikut (Wirawan, 2014: 293).

$Y=\alpha+\beta_{1} X_{1}+\beta_{2} X_{2}+\beta_{3} X_{3}+\varepsilon$

Keterangan:

$\mathrm{Y}=$ Disiplin Kerja

$\mathrm{X}_{1}=$ Komunikasi

$\mathrm{X}_{2}=$ Motivasi

$\mathrm{X}_{3}=$ Lingkungan Kerja Fisik

$\beta_{1}=$ Koefisen Regresi X1

$\beta_{2}=$ Koefisen Regresi X2

$\beta_{3}=$ Koefisen Regresi X3

$\alpha=$ Konstanta

$\varepsilon=$ Error

\section{HASIL DAN PEMBAHASAN}

Penelitian ini dilakukan untuk meneliti mengenai pengaruh komunikasi, motivasi, dan lingkungan kerja fisik terhadap disiplin kerja pada karyawan Warung Mina Cabang Peguyangan Denpasar. Data dikumpulkan dengan cara menyebarkan kuesioner ke Warung Mina Cabang Peguyangan Denpasar. Kuesioner disebarkan sebanyak 45 kuesioner. Karakteristik responden yang diteliti dalam penelitian ini meliputi: jenis kelamin, usia, tingkat pendidikan. Karakteristik responden dapat dilihat pada Tabel 2.

Berdasarkan Tabel 2. dapat dilihat bahwa Warung Mina Cabang Peguyangan Denpasar membutuhkan jumlah karyawan yang berimbang antara karyawan laki-laki dan perempuan jika dikaitkan dengan tuntutan tugas dan beban pekerjaan. Dilihat berdasarkan kriteria usia dapat dilihat bahwa karyawan di Warung Mina Cabang Peguyangan Denpasar yang paling dominan adalah yang berusia 21-30 tahun, karena pada usia ini karyawan lebih produktif. 
Tabel 2.

Karakteristik Responden

\begin{tabular}{|c|c|c|c|c|}
\hline \multirow{2}{*}{ No } & \multirow{2}{*}{ Keterangan } & \multirow{2}{*}{ Klarifikasi } & \multicolumn{2}{|c|}{ Jumlah } \\
\hline & & & Orang & Persentase \\
\hline \multirow{4}{*}{1} & \multirow{2}{*}{ Jenis Kelamin } & Laki-Laki & 23 & 51,11 \\
\hline & & Perempuan & 22 & 48,89 \\
\hline & \multicolumn{2}{|c|}{ Jumlah } & 45 & 100 \\
\hline & & $21-30$ & 33 & 73,33 \\
\hline \multirow[t]{4}{*}{2} & \multirow{2}{*}{ Usia } & $31-40$ & 10 & 22,22 \\
\hline & & $41-50$ & 2 & 04,45 \\
\hline & \multicolumn{2}{|c|}{ Jumlah } & 45 & 100 \\
\hline & & SMA/SMK & 41 & 91,11 \\
\hline \multirow[t]{3}{*}{3} & Pendidikan & Diploma & 3 & 06,67 \\
\hline & & S1 & 1 & 02,22 \\
\hline & \multicolumn{2}{|c|}{ Jumlah } & 45 & 100 \\
\hline
\end{tabular}

Berdasarkan kriteria pendidikan dapat dilihat bahwa responden dengan tingkat pendidikan SMA/SMK berjumlah 41 responden (91,11 persen), hal ini menyatakan bahwa Warung Mina Cabang Peguyangan membutuhkan tenaga kerja tamatan SMA/SMK dengan jurusan $F \& B$ Service dan Tata Boga yang memiliki skill dan keahlian dibidangnya, khususnya bidang pariwisata.

Pada analisis statistika inferensial menggunakan metode regresi linear berganda. Analisis ini digunakan untuk mengetahui pengaruh Komunikasi $\left(\mathrm{X}_{1}\right)$, Motivasi $\left(\mathrm{X}_{2}\right)$, Lingkungan Kerja Fisik $\left(\mathrm{X}_{3}\right)$ dan Disiplin Kerja $(\mathrm{Y})$. Hasil analisis regresi linear berganda disajikan pada Tabel 3 .

Tabel 3.

Hasil Uji Analisis Regresi Linear Berganda

\begin{tabular}{|c|c|c|c|c|c|}
\hline \multirow[t]{2}{*}{ Model } & \multicolumn{2}{|c|}{$\begin{array}{l}\text { Unstandardized } \\
\text { Coefficients }\end{array}$} & \multirow{2}{*}{$\begin{array}{c}\text { Standardized } \\
\text { Coefficients } \\
\text { Beta }\end{array}$} & \multirow[t]{2}{*}{$\mathbf{T}$} & \multirow[t]{2}{*}{ Sig. } \\
\hline & B & Std. Error & & & \\
\hline (Constant) & 2.326 & 2.031 & & 1.146 & .259 \\
\hline Komunikasi (X1) & .312 & .087 & .477 & 3.586 & .001 \\
\hline Motivasi (X2) & .175 & .050 & .325 & 3.512 & .001 \\
\hline $\begin{array}{l}\text { Lingkungan Kerja } \\
\text { Fisik (X3) }\end{array}$ & .213 & .074 & .381 & 2.886 & .006 \\
\hline R Square & & & & & .559 \\
\hline Adjusted R Square & & & & & .526 \\
\hline F hitung & & & & & 17.295 \\
\hline Sig. F & & & & & $.000^{\mathrm{b}}$ \\
\hline a. Dependent Variable: Y & & & & & \\
\hline
\end{tabular}

Koefisien regresi $\mathrm{X}_{1}$ sebesar 0,477 , nilai tersebut menunjukkan bahwa terdapat pengaruh positif antara komunikasi dan disiplin kerja karyawan Warung Mina Cabang Peguyangan Denpasar. Koefisien bertanda positif, artinya apabila komunikasi baik, maka disiplin kerja karyawan akan meningkat. 
Koefisien regresi $\mathrm{X}_{2}$ sebesar 0,325 , nilai tersebut menunjukkan bahwa terdapat pengaruh positif antara motivasi dan disiplin kerja karyawan Warung Mina Cabang Peguyangan Denpasar. Koefisien bertanda positif, artinya apabila motivasi tinggi, maka disiplin kerja karyawan juga akan meningkat.

Koefisien regresi $\mathrm{X}_{3}$ sebesar 0,381 , nilai tersebut menunjukkan bahwa terdapat pengaruh positif antara lingkungan kerja fisik dan disiplin kerja karyawan Warung Mina Cabang Peguyangan Denpasar. Koefisien bertanda positif, artinya apabila lingkungan kerja fisik dalam kondisi baik, maka disiplin kerja karyawan akan meningkat.

Jika nilai Asymp. Sig. (2-tailed) lebih besar taraf signifikansi yang ditetapkan yaitu 5 persen $(0,05)$, maka data telah berdistribusi normal. Berdasarkan hasil olah data, maka hasil uji normalitas disajikan pada Tabel 4.

Tabel 4.

Hasil Uji Normalitas

\begin{tabular}{cc}
\hline & Unstandardized Residual \\
\hline $\mathrm{N}$ & 45 \\
Kolmogorov-Smirnov Z & 0,746 \\
Asymp. Sig. (2-tailed) & 0,634 \\
\hline
\end{tabular}

Sumber: Data diolah, 2018

Berdasarkan hasil analisis, diperoleh hasil sebesar 0,634 >0,05 yang artinya data berdistribusi normal. Tabel 5 .

Berdasarkan hasil olah data, maka hasil uji multikolinearitas disajikan pada

Tabel 5.

Hasil Uji Multikolinearitas

\begin{tabular}{ccc}
\hline Model & \multicolumn{2}{c}{ Colinearity Statistic } \\
& Tolerance & VIF \\
\hline Komunikasi (X1) & 0,608 & 1,645 \\
Motivasi (X2) & 0,435 & 2,297 \\
Lingkungan Kerja Fisik & 0,617 & 1,620 \\
(X3) & & \\
\hline
\end{tabular}

Sumber: Data diolah, 2018

Hasil ini mengindikasikan bahwa tidak terdapat gejala multikolinear dari model regresi yang dibuat karena koefisien Tolerance semua variabel lebih besar dari 0,10 dan nilai VIF yang lebih kecil dari 10, sehingga pada model regresi ditemukan korelasi antar variabel bebas.

Pada Tabel 6. dapat dilihat bahwa nilai signifikansi dari variabel komunikasi sebesar 0,095, variabel motivasi sebesar 0,147, dan variabel lingkungan kerja fisik sebesar 0,652. Nilai tersebut lebih besar dari 0,05 yang berarti tidak terdapat pengaruh antara variabel bebas terhadap absolute residual. Dengan demikian, model yang dibuat tidak mengandung gejala heteroskedastisitas. 
Uji F dilakukan untuk menguji apakah semua variabel independen mempunyai pengaruh secara bersama-sama terhadap variabel dependen. Berdasarkan hasil olah data, maka hasil uji F disajikan pada Tabel 7.

Tabel 6.

Hasil Uji Heteroskedastisitas

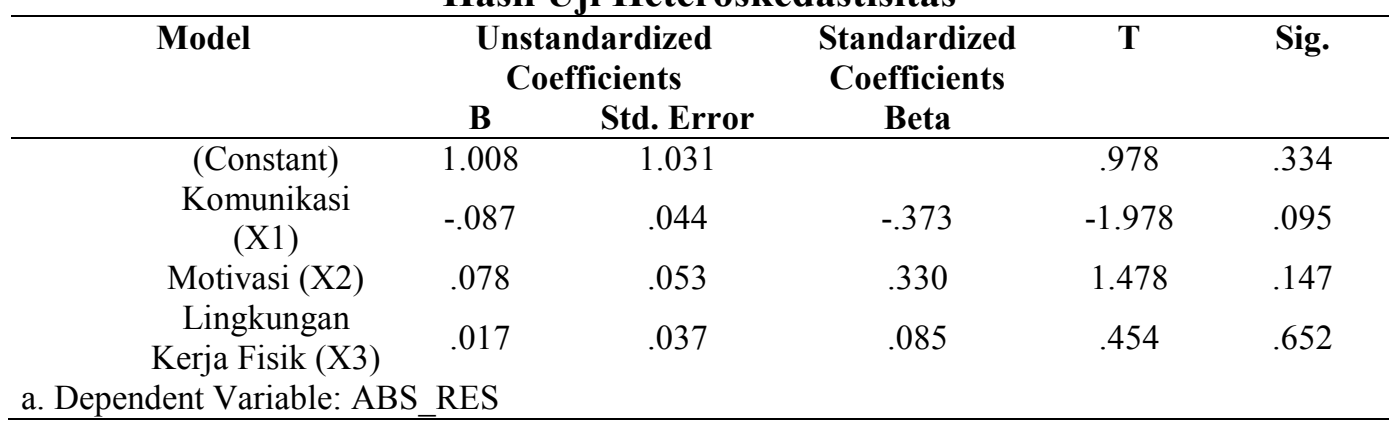

Sumber: Data diolah, 2018

Tabel 7.

Hasil Uji F

\begin{tabular}{llccccc}
\hline & Model & Sum of Squares & Df & Mean Square & F & Sig. \\
\hline \multirow{2}{*}{1} & Regression & 74.430 & 3 & 24.810 & 17.295 & $.000^{\mathrm{b}}$ \\
& Residual & 58.814 & 41 & 1.434 & & \\
& Total & 133.244 & 44 & & &
\end{tabular}

a. Dependent Variable: Y

b. Predictors: (Constant), X3, X1, X2

Sumber: Data diolah, 2018

Berdasarkan hasil uji, nilai signifikansi $\mathrm{F}$ adalah sebesar 0,000 yang lebih kecil dari $0,05(\mathrm{~F}<\alpha)$ yang berarti variabel bebas yaitu komunikasi $\left(\mathrm{X}_{1}\right)$, motivasi $\left(\mathrm{X}_{2}\right)$, dan lingkungan kerja fisik $\left(\mathrm{X}_{3}\right)$ berpengaruh signifikan secara serempak atau bersama-sama terhadap variabel terikat yaitu disiplin kerja $(\mathrm{Y})$.

Koefisien determinasi ( $R$ Square) pada intinya mengukur seberapa jauh kemampuan model dalam menerangkan variasi variabel terikat. Nilai yang mendekati 1 berarti variabel-variabel independen memberikan hampir semua informasi yang dibutuhkan untuk memprediksi variasi variabel dependen. Berdasarkan Tabel 3, besarnya nilai $\mathrm{R}$ square adalah sebesar 0,559 yang artinya sebesar 55,9 persen variasi disiplin kerja dipengaruhi oleh komunikasi, motivasi, dan lingkungan kerja fisik, sedangkan sisanya sebesar 44,1 persen dipengaruhi oleh faktor lain yang tidak dimasukkan ke dalam model penelitian.

Berdasarkan hasil analisis data pada Tabel 3, diketahui bahwa variabel komunikasi memiliki nilai koefisien beta positif sebesar 0,477 dengan nilai signifikansi 0,001 yang lebih kecil dari 0,05. Hasil ini mengindikasikan bahwa komunikasi berpengaruh positif dan signifikan terhadap disiplin kerja karyawan. Jika komunikasi semakin baik maka disiplin kerja karyawan akan semakin tinggi.

Berdasarkan hasil analisis data pada Tabel 3 diketahui bahwa variabel motivasi memiliki nilai koefisien beta positif sebesar 0,325 dengan nilai 
signifikansi 0,001 yang lebih kecil dari 0,05. Hasil ini mengindikasikan bahwa motivasi berpengaruh positif dan signifikan terhadap disiplin kerja karyawan. Jika motivasi semakin tinggi maka disiplin kerja karyawan akan semakin tinggi.

Berdasarkan hasil analisis data pada Tabel 3, diketahui bahwa variabel lingkungan kerja fisik memiliki nilai koefisien beta positif sebesar 0,381 dengan nilai signifikansi 0,006 yang lebih kecil dari 0,05 . Hasil ini mengindikasikan bahwa lingkungan kerja fisik berpengaruh positif dan signifikan terhadap disiplin kerja karyawan. Jika lingkungan kerja fisik semakin baik maka disiplin kerja karyawan akan semakin tinggi.

Hasil penelitian menunjukkan bahwa komunikasi berpengaruh positif dan signifikan terhadap disiplin kerja karyawan. Hal ini mengindikasikan bahwa komunikasi karyawan Warung Mina Cabang Peguyangan Denpasar dalam kondisi baik, karena karyawan Warung Mina Cabang Peguyangan Denpasar telah mampu mendiskusikan kepada pimpinan dan dengan karyawan lainnya mengenai masalah pekerjaan, berkoordinasi dengan sesama karyawan dalam memecahkan masalah, bertegur sapa kepada karyawan lainnya di tempat kerja, memberikan informasi kepada teman kerja lainnya yang berkaitan dengan tugas-tugas di tempat kerja, dan segala informasi mengenai tugas-tugas yang berikan oleh pimpinan sudah bisa dimengerti oleh karyawan

Hal ini sesuai dengan hipotesis satu $\left(\mathrm{H}_{1}\right)$ bahwa komunikasi berpengaruh positif dan signifikan terhadap disiplin kerja karyawan. Semakin baik komunikasi di dalam perusahaan maka disiplin kerja karyawan akan semakin tinggi. Hal ini sejalan dengan hasil penelitian yang dilakukan oleh Suaip \& Astuti (2015) yang menyatakan bahwa variabel komunikasi berpengaruh signifikan terhadap disiplin kerja pegawai. Dessy \& Wibawa (2015) menyatakan bahwa variabel komunikasi secara simultan dan secara parsial berpengaruh terhadap disiplin karyawan. Demikian juga penelitian dari Andriani (2018), Dila \& Rochmah (2015) menyatakan bahwa tingkat efektivitas komunikasi berpengaruh terhadap kedisiplinan pegawai. Azis \& Muchtar (2016) menyatakan bahwa komunikasi organisasi berpengaruh signifikan terhadap disiplin kerja pegawai.

Hasil penelitian menunjukkan bahwa motivasi berpengaruh positif dan signifikan terhadap disiplin kerja karyawan. Hal ini mengindikasikan bahwa motivasi karyawan Warung Mina Cabang Peguyangan Denpasar dalam kondisi baik, karena karyawan telah merasa penempatan kerja yang tepat dapat memotivasi karyawan menjalankan tugas dengan baik, kondisi pekerjaan yang menyenangkan dapat memotivasi karyawan untuk bekerja, setiap karyawan diberikan pelatihan yang sistematik untuk meningkatkan kemampuan atau skill karyawan dalam bekerja, dan setiap karyawan mendapatkan penjagaan kesehatan yang layak serta sesuai dengan kebutuhan karyawan.

Hal ini sesuai dengan hipotesis dua $\left(\mathrm{H}_{2}\right)$ bahwa motivasi berpengaruh positif dan signifikan terhadap disiplin kerja karyawan. Semakin tinggi motivasi dalam perusahaan maka disiplin kerja karyawan akan semakin meningkat. Hal ini sejalan dengan hasil penelitian yang dilakukan oleh Muharsih (2016) menyatakan bahwa terdapat pengaruh yang signifikan antara motivasi kerja terhadap disiplin kerja karyawan. Zahari (2015) menyatakan bahwa motivasi memiliki pengaruh positif dan signifikan terhadap disiplin kerja. Demikian juga penelitian dari Farid dkk. 
(2016) dan Sugiyatmi dkk. (2016) menyatakan bahwa motivasi kerja berpengaruh positif dan signifikan terhadap disiplin kerja karyawan. Penelitian yang dilakukan oleh Kokom (2017) menyatakan bahwa motivasi berprestasi berpengaruh secara signifikan terhadap disiplin kerjapegawai. Disiplin kerja pegawai salah satunya muncul karena adanya motivasi berprestasi sebab perilaku pegawai untuk memenuhi kebutuhannya harus dibarengi dengan pencapaian tujuan artinya apabila seseorang termotivasi dia akan mencoba sekuat tenaga mencapai tujuan.

Hasil penelitian menunjukkan bahwa lingkungan kerja fisik berpengaruh positif dan signifikan terhadap disiplin kerja karyawan. Hal ini mengindikasikan bahwa lingkungan kerja fisik di Warung Mina Cabang Peguyangan Denpasar dalam kondisi baik, karena karyawan telah mendapatkan penerangan yang cukup di tempat kerja, tidak menyilaukan mata serta mendapatkan distribusi cahaya yang merata, suhu udara di tempat kerja terasa nyaman pada saat bekerja di dalam maupun luar ruangan, penataan warna di tempat kerja sudah dalam kondisi penataan yang baik, kebersihan di tempat kerja sudah terjaga dengan baik, ruang gerak karyawan yang disediakan oleh perusahaan untuk melakukan pekerjaan sudah mencukupi, dan keamanan melakukan pekerjaan sudah dalam keadaan yang aman.

Hal ini sesuai dengan hipotesis tiga $\left(\mathrm{H}_{3}\right)$ bahwa lingkungan kerja fisik berpengaruh positif dan signifikan terhadap disiplin kerja karyawan. Semakin baik lingkungan kerja disik di perusahaan maka disiplin kerja karyawan akan semakin meningkat. Hal ini sejalan dengan hasil penelitian yang dilakukan oleh Haryono dkk. (2016) menyatakan bahwa secara simultan lingkungan kerja terhadap kedisiplinan karyawan. Permata \& Mujiati (2017) menyatakan bahwa lingkungan kerja fisik berpengaruh positif dan signifikan terhadap disiplin kerja. Hasil penelitian yang dilakukan oleh Puspitasari dkk. (2017) mengemukakan bahwa secara parsial menunjukkan bahwa lingkungan kerja berpengaruh terhadap disiplin kerja.

Permana dkk. (2015) menyatakan bahwa lingkungan kerja fisik berpengaruh positif dan signifikan terhadap disiplin kerja. Dengan adanya lingkungan kerja fisik yang baik, karyawan akan merasa nyaman dalam bekerja. Oleh karena itu, perusahaan harus selalu mengawasi lingkungan kerja perusahaan karena tanpa adanya lingkungan kerja yang baik, karyawan akan merasa tidak nyaman dan dapat mengganggu konsentrasi karyawan dalam bekerja. Pengaruh variabel lingkungan kerja terhadap disiplin kerja karyawan terbukti secara parsial berpengaruh positif dan signifikan terhadap disiplin kerja karyawan (Sugiyatmi dkk., 2016). Demikian juga penelitian yang dilakukan oleh Andriani (2018) menyatakan bahwa lingkungan kerja memiliki pengaruh positif dan signifikan terhadap disiplin kerja pegawai.

Hasil penelitian ini mendukung teori yang digunakan sebagai dasar dalam pembuatan hipotesis yang meneliti mengenai komunikasi, motivasi, dan lingkungan kerja fisik yang mempengaruhi disiplin kerja karyawan. Komunikasi karyawan yang baik, mendapatkan motivasi yang baik, merasa nyaman dengan lingkungan kerja fisik di tempat kerja, akan mampu meningkatkan disiplin kerja karyawan. Dalam hal berkomunikasi, karyawan Warung Mina Cabang Peguyangan Denpasar merasa nyaman dengan komunikasi antar atasan maupun 
karyawan lainnya sehingga karyawan mampu meningkatkan disiplin kerja. Oleh karena itu, perusahaan harus mampu mempertahankan komunikasi yang dimiliki karyawan, karena ketika komunikasi berhenti, kegiatan perusahaan dan kegiatan individual tidak akan terkoordinasi dalam suatu organisasi.

Dalam hal motivasi, karyawan Warung Mina Cabang Peguyangan Denpasar merasakan adanya motivasi yang tinggi antara karyawan dengan perusahaan. Hal ini menimbulkan adanya tingkat disiplin karyawan yang tinggi dalam perusahaan, karena dengan adanya motivasi yang tinggi, perusahaan akan mampu menciptakan sebuah kerjasama yang baik antar karyawan sehingga karyawan mampu meningkatkan disiplin dalam bekerja. Oleh karena itu, perusahaan harus menjaga dan memperhatikan motivasi yang diberikan kepada karyawannya.

Terkait dengan lingkungan kerja fisik, karyawan Warung Mina Cabang Peguyangan Denpasar merasa nyaman dan aman dalam bekerja dikarenakan perusahaan mampu menyediakan lingkungan kerja yang nyaman seperti tempat kerja yang selalu bersih, penataan tempat kerja yang menarik, ruang gerak karyawan sudah mencukupi, dan keamanan lingkungan di sekitar tempat kerja. Oleh karena itu, perusahaan harus mampu mempertahankan keadaan dan situasi lingkungan kerja untuk meningkatkan kedisiplinan karyawan dan demi mencapai tujuan perusahaan.

\section{SIMPULAN}

Komunikasi berpengaruh positif dan signifikan terhadap disiplin kerja karyawan. Hal ini menunjukkan bahwa ketika komunikasi diterapkan dengan baik maka disiplin kerja karyawan akan tinggi dalam perusahaan.

Motivasi berpengaruh positif dan signifikan terhadap disiplin kerja karyawan. Semakin tinggi motivasi yang dimiliki karyawan dalam bekerja maka akan semakin tinggi disiplin kerja karyawan. Lingkungan kerja fisik berpengaruh positif dan siginifikan terhadap disiplin kerja karyawan. Hal ini menunjukan bahwa semakin baik lingkungan kerja fisik yang diberikan perusahaan kepada karyawan maka akan semakin tinggi disiplin kerja karyawan.

Pimpinan Warung Mina Cabang Peguyangan Denpasar harus memperhatikan dan meningkatkan komunikasi antara sesama karyawan terutama dalam bertegur sapa. Dengan bertegur sapa akan mempererat hubungan antar sesama karyawan dan lebih memudahkan karyawan untuk bekerja sama dalam melakukan pekerjaan.

Pimpinan Warung Mina Cabang Peguyangan Denpasar sebaiknya memperhatikan bagaimana memberikan motivasi kepada karyawan dalam melaksanakan pekerjaannya, salah satunya dengan meningkatkan penjagaan kesehatan karyawannya. Perusahaan yang telah memberikan jaminan kesehatan berupa BPJS (Badan Penyelenggara Jaminan Sosial) yang sesuai dengan kebutuhan karyawannya diyakini dapat mendorong karyawan untuk bersedia bekerja dengan seluruh kemampuan yang dimiliki. Pimpinan Warung Mina Cabang Peguyangan Denpasar sebaiknya melakukan penataan ruangan pada dapur agar karyawan merasa nyaman dalam bekerja. 
Penataan ruangan akan mempermudah gerak karyawan dalam melakukan pekerjaan dengan cepat, tepat, dan akurat untuk membantu meningkatkan disiplin pribadi karyawan. Untuk mempertahankan disiplin kerja karyawan, maka Pimpinan Warung Mina Cabang Peguyangan Denpasar harus lebih sering mengadakan pelatihan pelayanan terhadap pelanggan dan memperjelas sanksi peraturan yang berlaku agar karyawan bisa mengerjakan tugas dan mencapai hasil sesuai dengan aturan yang berlaku. Karyawan yang selalu meanaati peraturan yang berlaku hendaknya diberikan penghargaan dan memberikan sanksi jika karyawan melanggar aturan yang berlaku.

\section{REFERENSI}

Ahyari, A. (2011). Manajemen Produksi Perencanaan Produksi. Yogyakarta: BPFE.

Amiroso, J., \& Mulyanto. (2015). Influence of Discipline, Working Environment, Culture of Organization and Competence on Workers' Performance through Motivation, Job Satisfaction (Study in Regional Development Planning Board of Sukoharjo Regency). European Journal of Business and Management, 7(36), 86-95. Retrieved from https://iiste.org/Journals /index.php/EJBM/ article/view/27525/29322

Andriani. (2018). Pengaruh Intensif, Komunikasi Internal dan Lingkungan Kerja terhadap Disiplin Kerja Pegawai di Kantor Camat Sangata Selatan Kabupaten Kutai Timur, 6(1), 128-138. Retrieved from http://ejournal.pin.or.id/site/wp-content/uploads/2017/11/pin_andriani (11-29-17-03-20-19).pdf

Ardana, I. K., Mujiati, N. W., \& Utama, I. W. M. (2014). Manajemen Sumber Daya Manusia (Edisi Pertama). Yogyakarta: Graha Ilmu.

Atambo, W. N., \& Momanyi, D. K. (2016). Effects of Internal Communication on Employee Performance: A Case Study of Kenya Power and Lighting Company, South Nyanza Region, Kenya. Imperial Journal of Interdisciplinary Research (IJIR), 2(5), 328-340. https://doi.org/10.1103/ PhysRevLett.72.2125

Azis, A., \& Muchtar, B. (2016). Pengaruh Komunikasi Organisasi dan Motivasi Kerja terhadap Disiplin Kerja Pegawai Pada Badan Kepegawaian Daerah (BKD) Kota Bukittinggi. Jurnal Riset Manajemen Bisnis Dan Publik, 4(1), 1-11. https://doi.org/10.1080/00173139109432020

Dessy, P. N. A., \& Wibawa, I. M. A. (2015). Pengaruh Komunikasi, Motivasi Kerja dan Pengalaman Kerja terhadap Disiplin Karyawan PT. Bank Pembangunan Daerah Bali Kantor Pusat. E-Jurnal Manajemen Universitas Udayana, 4(2), 399-410. Retrieved from https://www.ejurnal.com/2015/07/pengaruh-komunikasi-motivasi-kerja-dan.html

Elqadri, Z. M., Wardoyo, D. T. W., \& Priyono. (2015). The Influence of Motivation and Discipline Work against Employee Work Productivity 
Tona'an Markets. Review of European Studies, 7(12). https://doi.org/10.1182/blood-2002-05-1422

Farid, H. T., Hamid, D., \& Nurtjahjono, G. E. (2016). Pengaruh Motivasi Kerja Terhadap Kedisiplinan dan Kinerja Pegawai PT . PLN Distribusi Jawa Timur Area Malang. Jurnal Administrasi Bisnis (JAB), 32(1), 75-81. Retrieved from http://administrasibisnis .student journal .ub.ac.id /index.php/jab/article/view/1240/1422

Femi, A. F. (2014). The Impact of Communication on Workers' Performance in Selected Organisations in Lagos State, Nigeria. IOSR Journal Of Humanities and Social Science (IOSR-JHSS), 19(8), 75-82. Retrieved from http://www.iosrjournals.org/iosr-jhss/papers/Vol19-issue8/Version2/K019827582.pdf

Handoko, T. H. (2014). Manajemen Sumber Daya Manusia (Edisi Kedua). Yogyakarta: BPFE.

Haryono, Tri, A., Fathoni, A., \& Yugusna, I. (2016). Pengaruh Gaya Kepemimpinan Demokratis dan Lingkungan Kerja Terhadap Kinerja dan Kedisiplinan Karyawan. Journal Of Management, 2(2), 1-23. Retrieved from http://jurnal.unpand.ac.id/index.php/MS/article/download/515/501

Hasibuan, S. M. (2009). Manajemen Sumber Daya Manusia (Revisi). Jakarta: PT Bumi Aksara.

Iswara, I. G. A. R. P., \& Sudharma, I. Nyoman. (2013). Pengaruh Gaya Kepemimpinan, Budaya Organisasi dan Lingkungan Kerja FIsik Terhadap Disiplin Kerja Karyawan Dinas Pertanian Tanaman Pangan dan Hortikultura Kota Denpasar. E-Jurnal Manajemen Unud, 49(23-6), 671682. Retrievedfromhttps://www.google.com/url? sa $=\mathrm{t} \& \mathrm{rct}=\mathrm{j} \& \mathrm{q}=\&$ esrc $=$ s\&source $=$ web\&cd $=2 \& v e d=2$ ahUKEwjL_Ju36rDfAhXbfysKHbmNDJU QFjABegQICRAC\&url=https\%3A\%2F\%2Fmedia.neliti.co2media\%2Fpu blications\%2F254883-pengaruh-gaya-kepemimpinan-budaya-organi-71f7 ddf.pdf\&usg=AOvVaw0Jpt0GoEko82CHtuV210

Kasim, D., Rantetampang, A. L., \& Lumbantobing, H. (2016). Relationships of Work Discipline, Leadership, Training, and Motivation to Performance of Employees Administration Abepura Hospital Papua 2015. Journal of Sciences: Basic and Applied Research, 26(1), 154-164. Retrieved from http://gssrr.org/index.php?journal=Journal Of Basic And Applied \&page $=$ article\&op $=$ download\&path $\% 5 \mathrm{~B} \% 5 \mathrm{D}=5475 \&$ path $\% 5 \mathrm{~B} \% 5 \mathrm{D}=2782$

Kheruniah, A. E. (2013). A Teacher Personality Competence Contribution To A Student Study Motivation and Discipline To Fiqh Lesson. International Journal of Scientific \& Technology Research, 2(2), 108-112. Retrieved from http://www.ijstr.org/final-print/feb2013/A-Teacher-PersonalityCompetence-Contribution-To - A -Student -Study -Motivation And Discipline-To-Fiqh-Lesson.pdf 
Kokom. (2017). Pengaruh Motivasi Berprestasi terhadap Disiplin Kerja Pegawai dalam Mewujudkan Mutu Pelayanan Pendidikan. Jurnal Publik, 11(1), 114-124. Retrieved from https://journal .uniga.ac.id/ index.php /JPB/ article/ download/124/117

Mangkunegara, A. P. (2013). Manajemen Sumber Daya Manusia Perusahaan. Bandung: Remaja Rosdakarya.

Mangkunegara, A. P., \& Octorend, T. R. (2015). Effect of Work Discipline, Work Motivation and Job Satisfaction on Employee Organizational Commitment in the Company (Case Study in PT. Dada Indonesia). Universal Journal of Management, 3(8), 318-328. https://doi.org /10.13189/ujm.2015.030803

Martoyo, S. (2010). Manajemen Sumber Daya Manusia. Yogyakarta: BPFE.

Mudasir, Adiswisastra, Y., Hubeis, M., \& Sulistyani, D. (2014). The Effect of Leadership, Communication, and Discipline of the Population Administration Services in Palembang. Scientific Research Journal (SCIRJ), 2(8), 28-34. Retrieved from www.scirj.org/papers-0814/scirjP0814163.pdf\%0A\%0A

Mudiartha Utama, I. Wayan, Mujiati, N. W., \& Ardana, I. K. (2001). Buku Ajar Manajemen Sumber Daya Manusia. Denpasar: UPT Universitas Udayana.

Muharsih, L. (2016). Analisis Motivasi Kerja terhadap Disiplin Kerja Karyawan di Rumah Sakit Rawamangun Jakarta Timur. Psychopedia, 1(1), 56-68. Retrieved from http://journal.ubpkarawang.ac.id/index.php/Psikologi / article /view/39/38

Nitisemito, A. S. (2010). Manajemen Personalia dan Operasi: Manajemen Sumber Daya Manusia. Jakarta: Restasi Publiser Indonesia.

Permana, D. A., Hamid, D., \& Iqbal, M. (2015). TERHADAP DISIPLIN KERJA (Studi pada Karyawan PT . Bank Negara Indonesia ( Persero ) Kantor Cabang Utama Malang). Jurnal Administrasi Bisnis (JAB), 26(2), 110.Retrieved from http://administrasibisnis.studentjournal .ub.ac.id/ index.php/jab/article/view/1059/1242

Permata, S. A., \& Mujiati, N. W. (2017). Pengaruh Gaya Kepemimpinan dan Lingkungan Kerja Fisik terhadap Disiplin Kerja Pegawai Dinas Tenaga Kerja dan Transmigrasi Provinsi Bali. E-Jurnal Manajemen Unud, 6(5), 2280-2307. Retrieved from https://sinta.unud.ac.id /uploads/ dokumen_dir/775cb6dee5a0 a20ca1ba9683401ff3cd.pdf

Puspitasari, A. T., Nuraina, E., \& Utomo, S. W. (2017). Pengaruh Gaya Kepemimpinan, Kompensasi Dan Lingkungan Kerja Terhadap Disiplin Kerja Karyawan (Studi Pada Perusahaan Daerah Air Minum ( PDAM ) Lawu Tirta Kabupaten Magetan). Forum Ilmiah Pendidikan Akuntansi, 
5(1), 146-160. https://doi.org/10.1002/ejoc.201201075

Raymond, A. N. (2010). Manajemen Sumber Daya Manusia: Mencapai Keunggulan Bersaing. Jakarta: Salemba Empat.

Renah, A., \& Setyadi, P. D. (2014). The Influence of Organizational Culture , Working Environment and Educational Training on Motivation and Performance of Government Employees at West Kutai Regency East Kalimanatan. Journal of Business and Management, 6(30), 182-192. https://doi.org/10.1108/13620430710733631

Riyanto, S., Sutrisno, A., \& Ali, H. (2017). The Impact of Working Motivation and Working Environment on Employees Performance in Indonesia Stock Exchange. International Review of Management and Marketing, 7(3), 342-348. Retrieved from http://dergipark.gov.tr/download/articlefile/367764

Sarwani. (2016). The Effect of Work Discipline and Work Environment on the Perfomance of Employees. Sinergi, 6(2), 53-67. Retrieved from https://ejournal.unitomo.ac.id/index.php/feb/article/view/82/40

Saydam, G. (2010). Manajemen Sumber Daya Manusia. Yogyakarta: CV Andi Offset.

Sedarmayanti. (2014). Sumber Daya Manusia dan Produktivitas Kerja. Jakarta: Mandar Maju.

Shonubi, A. O., \& Akintaro, A. A. (2016). The Impact Of Effective Communication On Organizational Performance. The International Journal of Social Sciences and Humanities Invention, 3(3), 1904-1914. https://doi.org/10.18535/ ijsshi/v3i3.01

Suaip, M. R., \& Astuti, H. W. (2015). Pengaruh Komunikasi terhadap Upaya Meningkatkan Disiplin Kerja Pegawai PT. JAMSOSTEK (Persero) Bandar Lampung. Jurnal Bisnis Darmajaya, 1(1). Retrieved from https://jurnal .darmajaya.ac.id /index.php/Jurnal Bisnis /article/ download $/ 194 / 78$

Sugiyatmi, Minarsih, M. M., \& Gagah, E. (2016). Pengaruh Motivasi, Gaya Kepemimpin dan Lingkungan Kerja terhadap Disiplin Kerja serta Dampaknya terhadap Kinerja Karyawan di PT Bina San Prima. Journal Of Management, 2(2). Retrieved from http://jurnal .unpand.ac.id /index .php/MS/article/down load/534/520

Suniastuti, N. P. E., \& Suana, I. W. (2012). Pengaruh Gaya Kepemimpinan, Budaya Organisasi dan Komunikasi terhadap Disiplin Kerja Pegawai Perusahaan Daerah Parkir Kota Denpasar. E-Jurnal Manajemen Unud, 1(1), 90-109. Retrieved from https://e-jurnalpenelitian .blogspot.com /2015/05/jurnal-manajemen-pengaruh-gaya.html

Susita, D., Muslimah, W., \& AWS Waspodo, A. (2017). The Influence of Work 
Discipline and Work Environment On Organizational Commitment Employee of SBU Energy at PT Biro Klasifikasi Indonesia (Persero)

North Jakarta. JRMSI - Jurnal Riset Manajemen Sains Indonesia, 8(2), 275. https://doi.org/10.21009/JRMSI.008.2.06

Syamsuri, P. (2017). The Influence of Organizational Culture, Work Motivation, and Organizational Commitment to the Perfomance of Principals. Indonesian Journal of Educational Review, 4(1), 1-8. Retrieved from https:// docobook.com/1-the-influence-of-organizational-culture-work. html

Wirawan. (2009). Evaluasi Kinerja Sumber Daya Manusia: Teori Aplikasi dan Penelitian. Jakarta: Salemba Empat.

Yamsul, P., Surachman, Salim, U., \& Armanu. (2013). The Influence of Motivation and Organization Culture On Work Satisfaction And Organizational Commitment (Study On National Society Empowerment Program In Southeast Sulawesi Province). International Journal of Business and Management Invention ISSN (Online, 2(9), 2319-8028. Retrieved from http://ijbmi. org/papers /Vol(2)9 /Version-2/D02920180 25.pdf

Zahari, M. (2015). Pengaruh Motivasi Terhadap Disiplin Kerja Pegawai pada Dinas Perindustrian dan Perdagangan Provinsi Jambi. EKSIS: Jurnal Ilmiah Ekonomi Dan Bisnis, 6(1), 47-57. Retrieved from http://eksis. unbari.ac.id/index.php/EKSIS/article/view/117/48 